\title{
Assessment of Climate Change Impact on Crop yield and Evaluation of Coping Strategy using Crop Growth Simulation Model
}

\author{
J. Alam ${ }^{1 *}$ and R. K. Panda ${ }^{2}$ \\ ${ }^{1}$ Department of Agricultural Engineering, Purwanchal Campus, \\ Institute of Engineering, Tribhuvan University, Nepal \\ ${ }^{2}$ Agricultural and Food Engineering Department, IIT Kharagpur, India \\ *Corresponding author:ajawedc@ioe.edu.np
}

\begin{abstract}
Any change in climate will have implications for climate-sensitive systems such as agriculture, forestry and some other natural resources. Changes in solar radiation, temperature and precipitation will produce changes in crop yields and hence economics of agriculture. It is possible to understand the phenomenon of climate change on crop production and to develop adaptation strategies for sustainability in food production, using a suitable crop simulation model. CERES-Maize model of DSSAT v4.0 was used to simulate the maize yield of the region under climate change scenarios using the historical weather data at Kharagpur (1977-2007), Damdam (1974-2003) and Purulia (1986-2000), West Bengal, India. The model was calibrated using the crop experimental data, climate data and soil data for two years (1996-1997) and was validated by using the data of the year 1998 at Kharagpur. The change in values of weather parameters due to climate change and its effects on the maize crop growth and yield was studied. It was observed that increase in mean temperature and leaf area index have negative impacts on maize yield. When the maximum leaf area index increased, the grain yield was found to be decreased. Increase in $\mathrm{CO}_{2}$ concentration with each degree incremental temperature decreased the grain yield but increase in $\mathrm{CO}_{2}$ concentration with fixed temperature increased the maize yield. Adjustments were made in the date of sowing to investigate suitable option for adaptation under the future climate change scenarios. Highest yield was obtained when the sowing date was advanced by a week at Kharagpur and Damdam whereas for Purulia, the experimental date of sowing was found to be beneficial.
\end{abstract}

Keywords: Climate change, CERES-Maize, DSSAT v4.0, crop simulation, yield.

\section{Introduction}

Maize is the third most important food crop in the world among global food crops in terms of production, following rice and wheat and is grown in various climates through out the world. In India, it is grown over an area of 6.4 million hectares with total production of about 11.5 million 
tonnes. Based on climate records, average global temperatures at the earth's surface are rising. Since global records began in the mid $19^{\text {th }}$ century, the five warmest years have occurred during the 1990s and 10 of the 11 warmest years have occurred since 1980 [30]. Climate is changing mainly due to increasing concentration of greenhouse gases and is affecting many economic sectors, mainly agriculture and forestry. A change in climatic variables is predicted to increase the earth's mean surface temperature and is likely to be accompanied by increased precipitation [8]. Field crop production is significantly affected by climatic variables because photosynthetically active radiation, air temperature and water are the driving forces for crop growth $[34,33]$. It is now well recognized that crop production is very sensitive to climate change with varying effects according to region [27]. In the Indian context, Kumar and Parikh [20] estimated the macro level impacts of climate change using a distinct approach. They showed that under doubled carbon dioxide concentration levels in the later half of twenty-first century, the gross domestic product would decline by 1.4 to $3 \%$ points due to climate change. Increasing $\mathrm{CO}_{2}$ level increases crop production due to higher rates of photosynthesis and increased water use efficiency, especially at low water or high nutrient availability [24]. Mall et al. [26] provided an excellent review of climate change impact studies on Indian agriculture, mainly from the perspective of physical impact.

The Decision Support System for Agro-technology Transfer (DSSAT), which is a combination of several dynamic crop simulation models, is one such model that can predict accurately the growth, development and yield of crops with the help of soil, daily weather and management inputs, to aid farmers in developing long-term rotational strategies. DSSAT is the major product of the IBSNAT (International Benchmark Site Network for Agrotechnology Transfer) project, initiated in 1982 [37]. Crop simulation models (CSMs) have been used extensively in India to quantify the magnitude of improvement in yield potential at different levels of management and climatic variability and proved that the simulation studies can be used in supplement to field studies [1]. Oosterom et al. [29] used crop simulation models as agronomic tools to assess the growth and development, biomass accumulation and yield of crops. Steiner et al. [36] used CERES crop growth simulation model for maize, sorghum and winter wheat grown at Bushland, Texas to predict evapotranspiration and crop growth parameters like leaf area index and total dry matter accumulation under water stress. The CERES-Maize model includes the capability to simulate the effects of increased atmospheric $\mathrm{CO}_{2}$ concentrations on photosynthesis and water use by the crop. Daily potential transpiration calculations are modified by the $\mathrm{CO}_{2}$ concentrations [22, 10, 31]. Wafula [38] evaluated CERES-Maize under different management strategies and tested the yield potential under different sowing dates, planting density and rates of fertilizer $\mathrm{N}$ application. Bannayan et al. [5] used CERES-Maize model to check the photothermal impact on maize performance and found that the model is suitable as a modeling tool in simulation studies to examine the effects of the genotype by environment interaction on growth, development and yield. White et al. [40] tested the CERES models in response to temperature and evaluated the models for predicting the growth, biomass partitioning and yield of wheat and maize crops. In order to overcome the predicted limitations for crop production in the future, there is also a need to identify and evaluate the suitable agronomic practices such as altered sowing date and 
selection of improved varieties with increased production at high temperature and other useful traits. These adaptation strategies may potentially lessen future yield losses from climate change or may improve yields in regions where beneficial climate changes occur [15]. Keeping this in view, the study was conducted at IIT Kharagpur during 2008/09 with the objectives: (i) to simulate the effect of climate change on maize growth and yield parameters and (ii) to evaluate optimum planting date for maize using CERES- Maize model.

\section{Materials and Methods}

\subsection{Site Description}

The current study was carried out at Agricultural and Food Engineering Department, Indian Institute of Technology, Kharagpur, India $\left(22^{\circ} 19^{\prime} \mathrm{N}\right.$ latitude and $87^{\circ} 19^{\prime} \mathrm{E}$ longitude and $48 \mathrm{~m}$ above the mean sea level). The soil of this region is of lateritic type with sandy loam texture, which is taxonomically grouped under the group 'Alfisol'. The climate of Kharagpur is classified as sub-humid, subtropical. The site receives an average rainfall of $1200 \mathrm{~mm}$ with $70-75 \%$ of the total rainfall in the monsoon during June to October. The average temperature varies between 21 ${ }^{\circ} \mathrm{C}$ and $32{ }^{\circ} \mathrm{C}$.

The study was extended to Dumdum (latitude $22.38^{\circ} \mathrm{N}$, longitude $88.38^{\circ} \mathrm{E}$ ) and Purulia (latitude $23.2^{\circ} \mathrm{N}$, longitude $88.28^{\circ} \mathrm{E}$ ) to assess the impact of climate change on maize growth and yield using the calibrated crop growth model at Kharagpur. Only climatic and soil data were used to run the model at Dumdum and Purulia. Soil properties at Dumdum and Purulia were obtained from National Bureau of Soil Survey and Land Use Planning (NBSSLUP), Kolkata.

\subsection{Experimental Crop Data}

The experimental crop data required for calibration and validation of the CERES-Maize model were collected from previous experiments conducted for the period of 1996-98 at the experimental farm of the Agricultural and Food Engineering Department, Indian Institute of Technology, Kharagpur, India. The local high yielding maize variety namely "Vijaya Composite" was considered as the experimental crop in the study. The field experiments were designed as per randomized block design (RBD) with irrigation schedules or treatments as the factors. There were four irrigation treatments in all the three experiments. There were three replications for each treatment. A standard seed rate of $17-20 \mathrm{~kg} / \mathrm{ha}$ was used. The seeds were sown at a row spacing of $60 \mathrm{~cm}$ and a plant spacing of $25 \mathrm{~cm}$ during all the three experiments. The fertilizer dose of N:P:K was 100:60:40 kg/ha. The irrigation treatments consisted of irrigation scheduling based on maximum allowable depletion (MAD) of the total available soil water (ASW) criteria. Each irrigation treatment was based on a predefined level of MAD, which was a fixed percent of the total ASW. Irrigation water was applied whenever the threshold value of MAD for the particular irrigation treatment was attained. The irrigation treatments considered in the study were: $T 1=10 \%$ maximum allowable depletion of available soil water, $T 2=30 \%$ MAD of ASW, T3 $=45 \%$ MAD of ASW, T4 $=60 \%$ MAD of ASW. 


\subsection{Weather Data}

Daily values of the weather variables such as: solar radiation, maximum and minimum temperature and rainfall for the experimental period were obtained from an automatic weather station installed close to the experimental crop field. Thirty one years weather data (1977-2007) of Kharagpur were collected for use in the CERES-Maize model. The climatic data for Dumdum (1974-2003) and Purulia (1986-2000) were collected from the India Meteorological Department, Pune.

\subsection{Analysis of Trend}

Trend is a long term variation in a time series. It tells whether a particular data set is increasing or decreasing over the period of time. A time series is a sequence of observations which are ordered in time or space. The Mann-Kendall non-parametric test was used to analyze the trend of variation in climatic parameters such as: solar radiation, maximum temperature and minimum temperature at Kharagpur, Dumdum and Purulia. The Mann-Kendall test is considered as the most appropriate approach for analysis of trend in climatological time series data $[12,11,7]$. Brief description about the Mann-Kendall test is given below.

Let $x_{1}, x_{2}, \ldots \ldots x_{n}$ represents $\mathrm{n}$ data points where $\mathrm{x}_{\mathrm{j}}$ represents the data points at time $j$. Then the Mann-Kendall statistic (S) is given by

$$
S=\sum_{k=1}^{n-1} \sum_{j=k+1}^{n} \operatorname{sign}\left(x_{j}-x_{k}\right)
$$

where

$$
\begin{aligned}
& \operatorname{sign}\left(x_{j}-x_{k}\right)=1 \text { if }\left(x_{j}-x_{k}\right)>0 \\
& \operatorname{sign}\left(x_{j}-x_{k}\right)=0 \text { if }\left(x_{j}-x_{k}\right)=0 \\
& \operatorname{sign}\left(x_{j}-x_{k}\right)=-1 \text { if }\left(x_{j}-x_{k}\right)<0
\end{aligned}
$$

Variance of $\mathrm{S}, \operatorname{VAR}(\mathrm{S})$ is calculated by the following equation,

$$
V A R(S)=\frac{1}{18}\left[n(n-1)(2 n+5)-\sum_{p=1}^{g} t_{p}\left(t_{p}-1\right)\left(2 t_{p}+5\right)\right]
$$

where $n$ is the number of data points, $g$ is the number of tied group and $t_{p}$ is the number of data points in the $\mathrm{p}^{\mathrm{th}}$ group. 
Normalized test statistic (Z) is calculated as follows,

$$
\begin{aligned}
& Z=\frac{S-1}{[\operatorname{VAR}(S)]^{1 / 2}} \text { if }(S>0) \\
& Z=0 \text { if }(S=0) \\
& Z=\frac{S+1}{[\operatorname{VAR}(S)]^{1 / 2}} \text { if }(S<0)
\end{aligned}
$$

The probability associated with this normalized test statistic is calculated as follows,

$$
f(z)=\frac{1}{\sqrt{2 \Pi}} e^{\frac{z^{2}}{2}}
$$

\subsection{CERES-Maize Model}

DSSAT (Decision Support System for Agrotechnology Transfer) was used for simulating crop growth parameters [13]. The model was developed under the International Benchmark Sites Network for Agrotechnology Transfer (IBSNAT) project. DSSAT is integrated software of different computer programmes, which can facilitate the application of crop simulation models in research and decision-making. For the present study CERES model from DSSAT v4.0 was used for maize crop. In CERES model, the input and output files carry data related to soil, weather, genotype and crop. The file structure can be described with three different categories: input files, output files and experimental performance data files. Input files are further divided into those dealing with the experiment, weather and soil, and the characteristics of different genotypes (crop and cultivar). The files can be recognized by the extension used e.g. '.wth' for weather file, '.sol' for soil file, '.exp' for experimental file and '.cul' for cultivar file. The input and output file related to soil, weather and cultivar were developed and used in this study. Crop growth is simulated by employing a carbon balance approach in a source-sink system [32]. Daily crop growth rate is calculated as:

$$
P C A R B=\frac{R U E^{*} P A R}{P L T O P}\left(1-e^{\left(-k^{*} L A I\right)}\right) * C O_{2}
$$

where PCARB $=$ Potential growth rate, g/plant, RUE = Radiation use efficiency (g dry matter/ MJ PAR $),$ PAR $=$ Photo synthetically active radiation $\left(\mathrm{MJ} / \mathrm{m}^{2}\right)$, PLTOP $=$ Plant population, plant $/ \mathrm{m}^{2}, \mathrm{~K}=$ Light extinction factor, $\mathrm{LAI}=$ Green leaf area index, $\mathrm{CO}_{2}=\mathrm{CO}_{2}$ modification factor.

\subsection{Simulating the Impact of Temperature and $\mathrm{CO}_{2}$}

Simulation of the duration of each phenological stage uses the concept of thermal time [32]. Because the time scale of plants is closely coupled with its thermal environment, thinking of thermal time as a plant's view of time is appropriate. Thermal time has units of ${ }^{\circ} \mathrm{C}$ day. The simplest and most useful definition of thermal time $t_{d}$ is 


$$
t_{d}=\sum_{i=1}^{n}\left(T_{a}-T_{b}\right)
$$

where $T_{a}$ is daily mean air temperature, $T_{b}$ is the base temperature at which development stops and $\mathrm{n}$ is the number of days of temperature observations used in the simulation. The calculation of $T_{a}$ is accomplished in the CERES models by averaging the daily maximum and minimum temperatures under most circumstances.

\subsection{Fixed Climate Change Scenarios}

Changes in Earth's climate have been projected by the end of this century because some atmospheric 'greenhouse' gases, among them carbon dioxide $\left(\mathrm{CO}_{2}\right)$, are increasing $[2,14]$. It is expected that atmospheric $\mathrm{CO}_{2}$ concentration will double sometime during this century if fossil fuels burning continues and air temperature is predicted to rise 1.5 to $5{ }^{\circ} \mathrm{C}$ with more than $90 \%$ likelihood by $2100[3,25]$. As a consequence of a possible increase in atmospheric $\mathrm{CO}_{2}$ concentration and associated climate changes, several studies have been conducted in order to predict the effects of climate change on crop growth, development, and yield. A hypothetical study was done to determine the potential yield of maize under 30 different combinations of $\mathrm{CO}_{2}$ and temperature, including the fixed increment in $\mathrm{CO}_{2}(380,400,500,600,700 \mathrm{ppm})$ and temperature (ambient, $+1,+2,+3,+4$ and $+5^{\circ} \mathrm{C}$ ) individually and with all combinations of these levels of $\mathrm{CO}_{2}$ and temperature. For simulating effect of temperature change the daily maximum and minimum temperatures were increased by $1-5{ }^{\circ} \mathrm{C}$ individually in CERES-Maize model and yield was calculated accordingly. Similarly climate change scenarios under different levels of $\mathrm{CO}_{2}$ were applied by changing ambient $\mathrm{CO}_{2}$ in CERES-Maize.

\subsection{Sowing Date Evaluation}

The various possible agro adaptation measures include alternate sowing dates, water management, different tillage depths, nutrient management, improved heat resistant varieties etc. Among these alternate sowing date was applied to the calibrated CERES-Maize model and their impact on the crop yield was determined. The maize yield was simulated for 4 weeks before and 4 weeks after the actual date of sowing (6 February) at the interval of one week. The percentage change in the yield compared with yield at conditions similar during base period was considered to determine the adaptation measures which will mitigate the negative effects of climate change.

\section{Results and Discussion}

The model was calibrated using the daily weather data and experimental-crop data on grain yield, above ground dry matter and maximum leaf area index. The well-watered treatment $(10 \%$ Maximum Allowable Depletion) of each experiment was selected for calibration. The values of genetic coefficients were estimated using the best-fit method. Model was calibrated for each experiment separately and an average value of each genetic coefficient was considered for simulation. The model was calibrated using two years of field experiment in 1996 and 1997. Then the model was validated using the crop data of the year 1998. The genetic coefficients 
determined by the process of calibration were used for validation. Statistical analysis was performed to evaluate the performance of CERES-Maize model in simulating the crop variables. The values of statistical test parameters such as: mean error (ME), root mean square error (RMSE) and model efficiency (EF) revealed that the CERES-Maize Model simulated the crop variables with considerable accuracy and thereby can be recommended for further use under similar agro-climatic conditions (Table 1).

Table 1: Statistics for comparison amongst simulated and measured values of crop parameters

\begin{tabular}{|l|c|c|c|c|}
\hline \multicolumn{1}{|c|}{ Crop parameters } & $\mathbf{R}^{\mathbf{2}}$ & RMSE & ME & EF \\
\hline Grain yield (kg/ha) & 0.82 & 510 & 233 & 0.807 \\
\hline Above ground dry matter (kg/ha) & 0.85 & 530 & 279 & 0.817 \\
\hline Leaf area index & 0.86 & 0.138 & 0.074 & 0.84 \\
\hline
\end{tabular}

\subsection{Analysis of Trend}

Trend of variation in climatic data was analyzed using the Mann-Kendall method, which is a non parametric test for identifying trends in time series data. The test compares the relative magnitude of sample data. Solar radiation, maximum temperature and minimum temperature during the crop growth period (February to May) at Kharagpur (1977-2007), Dumdum (19742003) and Purulia (1986-2000) were analyzed to check their trend. The data values were evaluated as an order time series and each data value was compared with all subsequent data values.

Table 2: Mann-Kendall trend results for solar radiation, maximum temperature and minimum temperature at Kharagpur, Dumdum and Purulia

\begin{tabular}{|l|c|c|c|c|}
\hline $\begin{array}{c}\text { Weather } \\
\text { Parameters }\end{array}$ & $\begin{array}{c}\text { Mann-Kendall } \\
\text { statistic (S) }\end{array}$ & $\begin{array}{c}\text { Normalized test } \\
\text { statistic (Z) } \\
\text { Kharagpur }\end{array}$ & Probability & Trend* \\
\hline \multicolumn{5}{|c|}{. } \\
\hline Solar radiation & 85 & 1.43 & 0.86 & No Trend \\
\hline Maximum temperature & 58 & 0.97 & 0.78 & No Trend \\
\hline Minimum temperature & -45 & -0.75 & 0.70 & No Trend \\
\hline \multicolumn{5}{|c|}{ Dumdum } \\
\hline Solar radiation & 142 & 2.56 & 1 & Increasing \\
\hline Maximum temperature & -38 & -0.67 & 0.68 & No Trend \\
\hline Minimum temperature & -126 & -2.25 & 0.99 & Decreasing \\
\hline
\end{tabular}




\begin{tabular}{|l|c|c|c|c|}
\hline \multicolumn{5}{|c|}{ Purulia } \\
\hline Solar radiation & -5 & -0.19 & 0.65 & No Trend \\
\hline Maximum temperature & 24 & 1.13 & 0.77 & No Trend \\
\hline Minimum temperature & -27 & -1.28 & 0.81 & No Trend \\
\hline
\end{tabular}

* At 5\% level of significance.

The Mann-Kendall statistic (S), variance (VAR(S)), normalized test statistic (Z) and probability associated with this normalized test statistic were calculated by using the method described in section 2.3. Microsoft Excel function NORMSDIST, was used to calculate the probability associated with normalized test statistics. At a particular probability level of significance (95\%), the trend is said to be decreasing if normalized test statistic $(Z)$ is negative and the computed probability is greater than the significance level. The trend is said to be increasing if the normalized test statistic $(Z)$ is positive and the computed probability is greater than level of significance and there is no trend if the computed probability is less than the level of significance [16]. The results of Mann-Kendall test on solar radiation, maximum temperature and minimum temperature are summarized in Table 2 for Kharagpur, Dumdum and Purulia. The trend analysis at $5 \%$ of level of significance showed that there is no trend for solar radiation, maximum temperature and minimum temperature at Kharagpur and Purulia. There is increasing trend for solar radiation, decreasing trend for minimum temperature and no trend for maximum temperature at Dumdum.

\subsection{Effect of Temperature on Yield of Maize}

Temperature exerts a major effect on the rate at which plants develop and growth can be retarded when the temperature is either too low or too high [28]. For a given minimum temperature, increasing maximum temperature up to $35{ }^{\circ} \mathrm{C}$ accelerate both development towards anthesis and maturity. An increase in temperature above the optimum temperature results in a reduction of the developmental rate [6]. There is a strong relationship between crop development and the mean daily temperature [39]. In general, higher temperatures during the growing season will be associated with higher radiation and a demand for more water, which along with elevated $\mathrm{CO}_{2}$ concentration are major factors that have to be considered in any impact assessment. As shown in Fig. 1, rising mean temperatures can lead to decrease in maize yield as revealed during the years 1979, 1986, 1991 and 1999 which supports the earlier findings of Schlenker and Roberts [35]. Similar trends of decreased yield with increased mean temperature were found at Dumdum (Fig. 2) and Purulia (Fig. 3). 


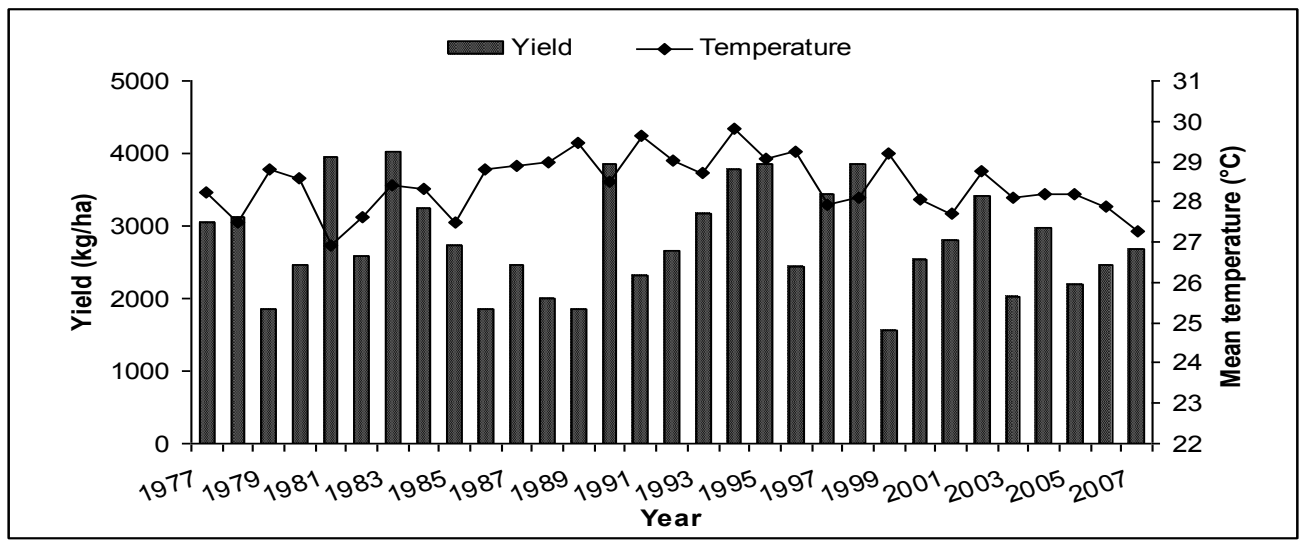

Fig. 1: Variation in maize yield with mean temperature at Kharagpur for period 1977-2007

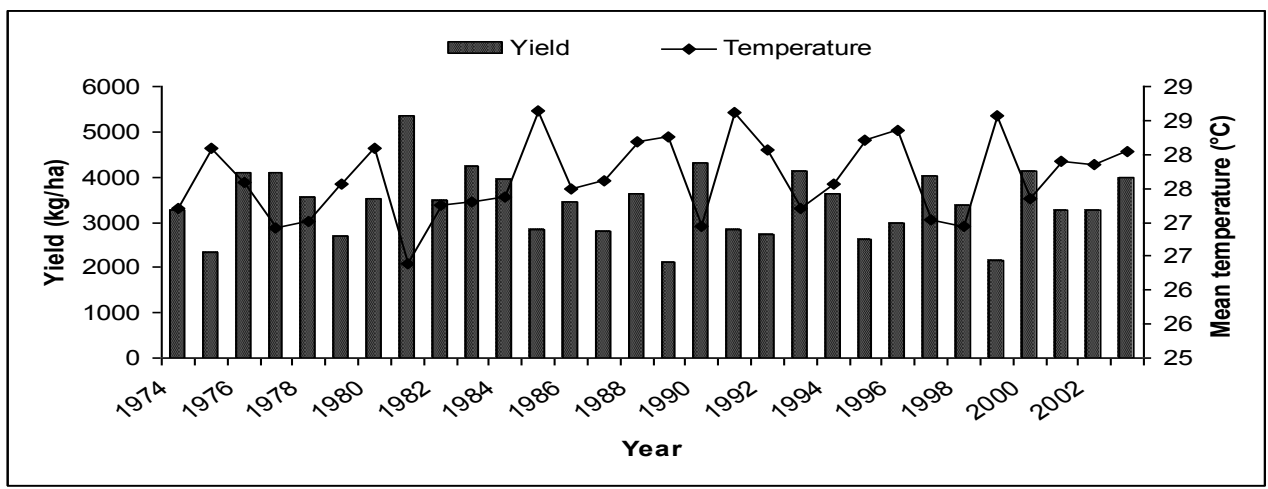

Fig. 2: Variation in maize yield with mean temperature at Dumdum for period 1974-2003

A negative yield response to diurnal temperature range (DTR; the difference between daily maximum and minimum temperature), coupled with a negative yield response to average temperature in most regions, indicates that temperature increase is more harmful during day than at night.

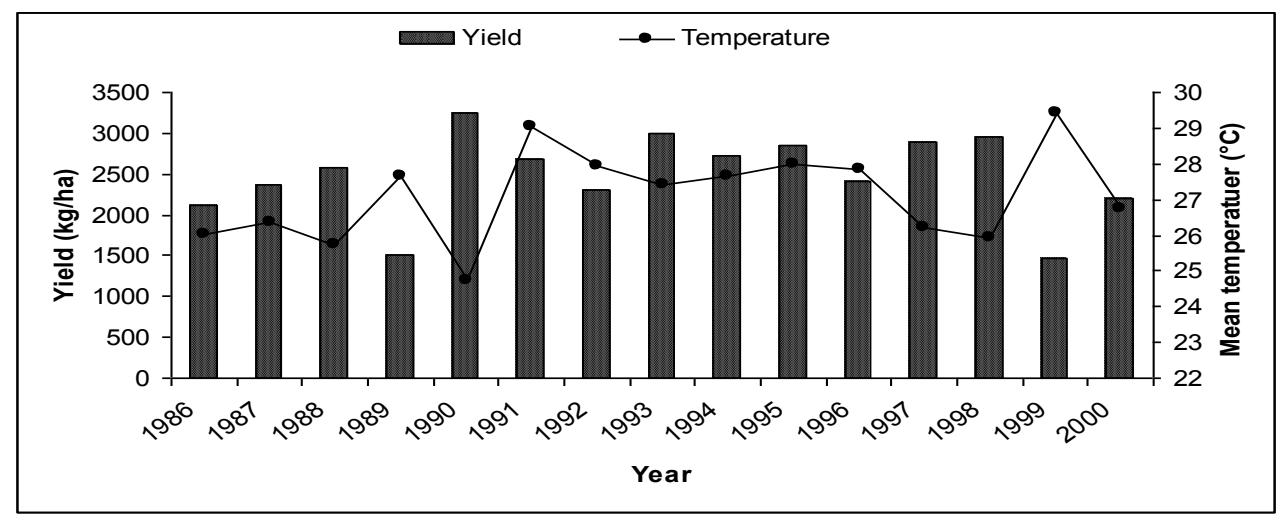

Fig. 3: Variation in maize yield with mean temperature at Purulia for period 1986-2000 


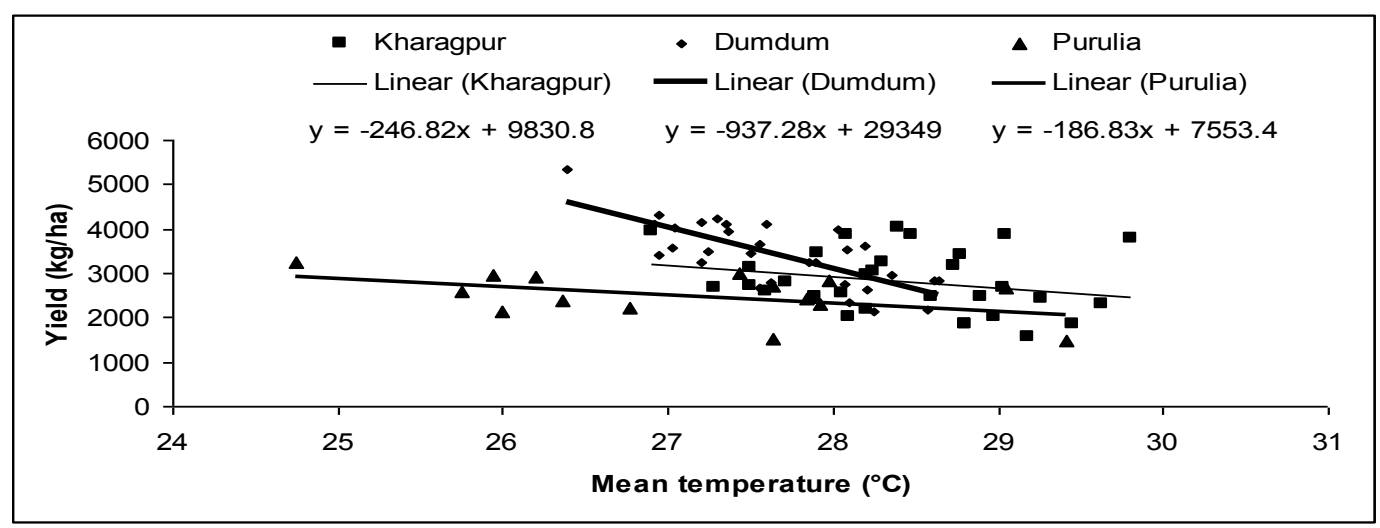

Fig. 4: Relation between mean temperature and maize yield at Kharagpur, Dumdum and Purulia

In studies with the EPIC crop simulation model, Dhakhwa and Campbell [9] concluded that DTR increase resulted in lower maize yields in the US because of greater evapotranspiration losses, and consequent water stress. A recent study of US maize yields that utilized daily minimum and maximum temperature data provided strong empirical evidence that yield decreased nonlinearly with temperatures above $25^{\circ} \mathrm{C}$, with even short periods above $30^{\circ} \mathrm{C}$ resulting in significant yield losses [35]. In general, higher temperatures during growing season will be associated with higher radiation and a demand for more water, which along with elevated $\mathrm{CO}_{2}$ concentration are major factors that have to be considered in any impact assessment. Yield-temperature response curves (Fig. 4) show that there is a decreasing trend in grain yield of maize per degree rise in seasonal mean temperature.

\subsection{Effect of Leaf Area Index on Growth and Yield of Maize}

Plant leaf area has an important influence on light interception and dry matter production. The rate of leaf area expansion is an important component of plant growth that is quite sensitive to environmental stress. If the maximum LAI increases, biomass production increases due to increased rate of photosynthesis leading to less accumulation in the form of grain yield due to low partitioning. Historical weather data was used for simulation of crop growth and yield at Kharagpur, Dumdum and Purulia using the crop growth simulation model. It was found from the simulation that in most of the years, when maximum leaf area index (LAI) increased, crop yield decreased. On the other hand, crop yield increased with the decrease in maximum leaf area index. At Kharagpur, in the year 1979 (Fig. 5), maximum LAI was found to be 3.28 and crop yield was $1852 \mathrm{~kg} / \mathrm{ha}$, where as in 1981, maximum LAI was found to be 2.5 with crop yield as $3940 \mathrm{~kg} / \mathrm{ha}$. This shows that the LAI has significant influence on maize yield at Kharagpur. The effect of leaf area index on the yield of maize at Dumdum (Fig. 6) and Purulia (Fig. 7) was found to follow a trend that when the leaf area index was higher the maize yield was lower and vice versa as shown in Fig. 8. 


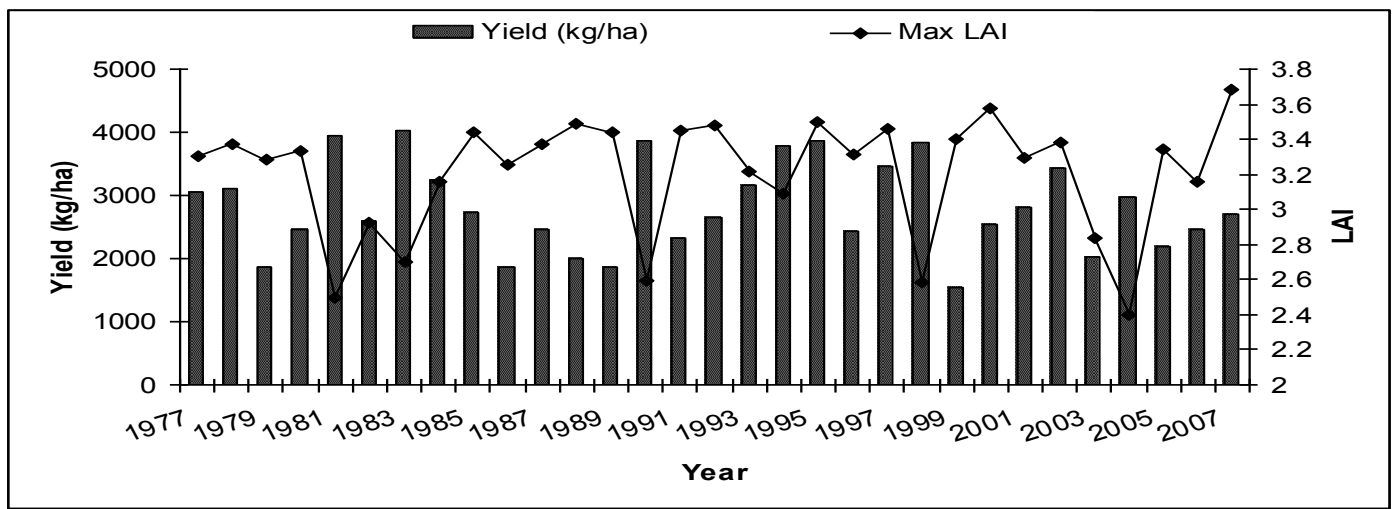

Fig. 5: Variation in maize yield with maximum LAI at Kharagpur for period 1977-2007

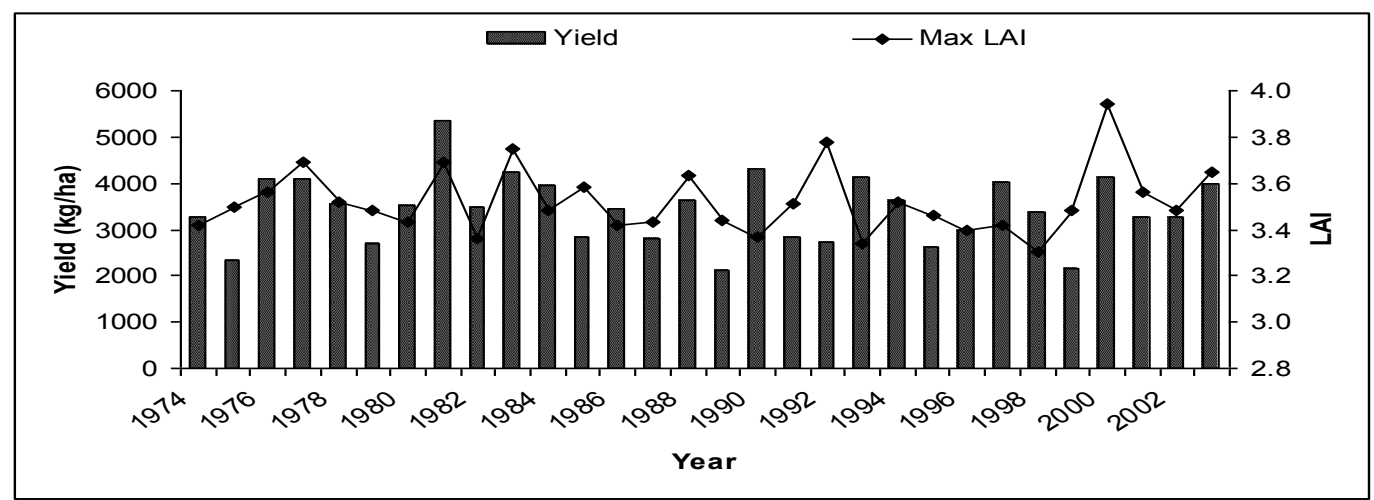

Fig. 6: Variation in maize yield with maximum LAI at Dumdum for period 1974-2003

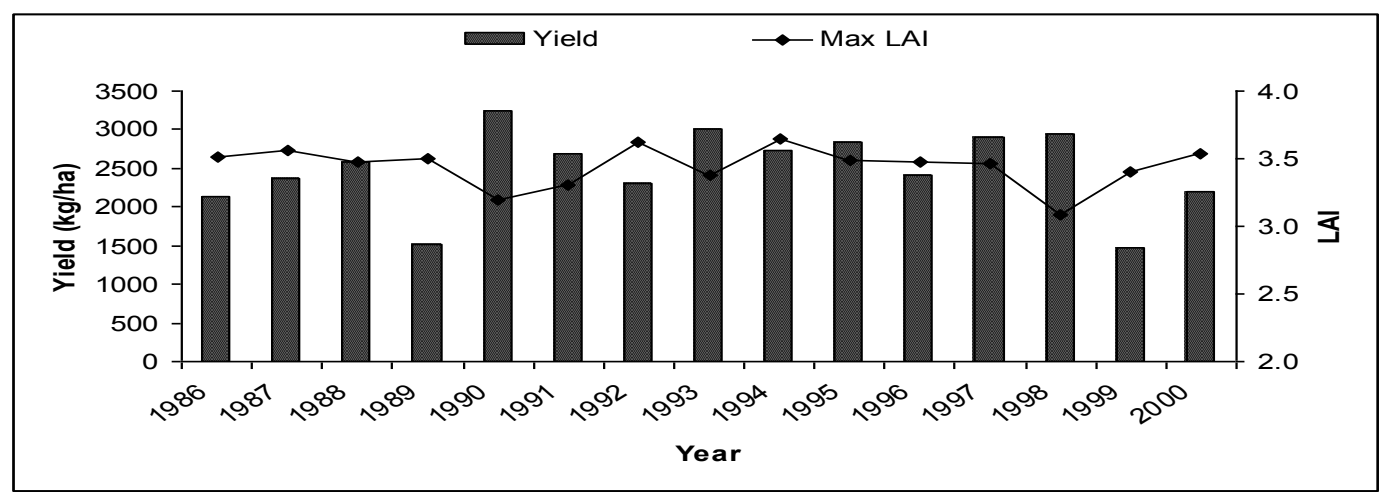

Fig. 7: Variation in maize yield with maximum LAI at Puraliya for period 1986-2000

Leaf growth is more sensitive to plant water deficits than photosynthesis. Lower temperature or moderate drought stresses reduce the expansion growth more than that if photosynthesis is reduced; causing increase in specific leaf weight and increasing the proportion of assimilate partitioned to the roots. Maximum foliar development retards grain development, as a result, crop yield decreases with the increase in maximum LAI. 


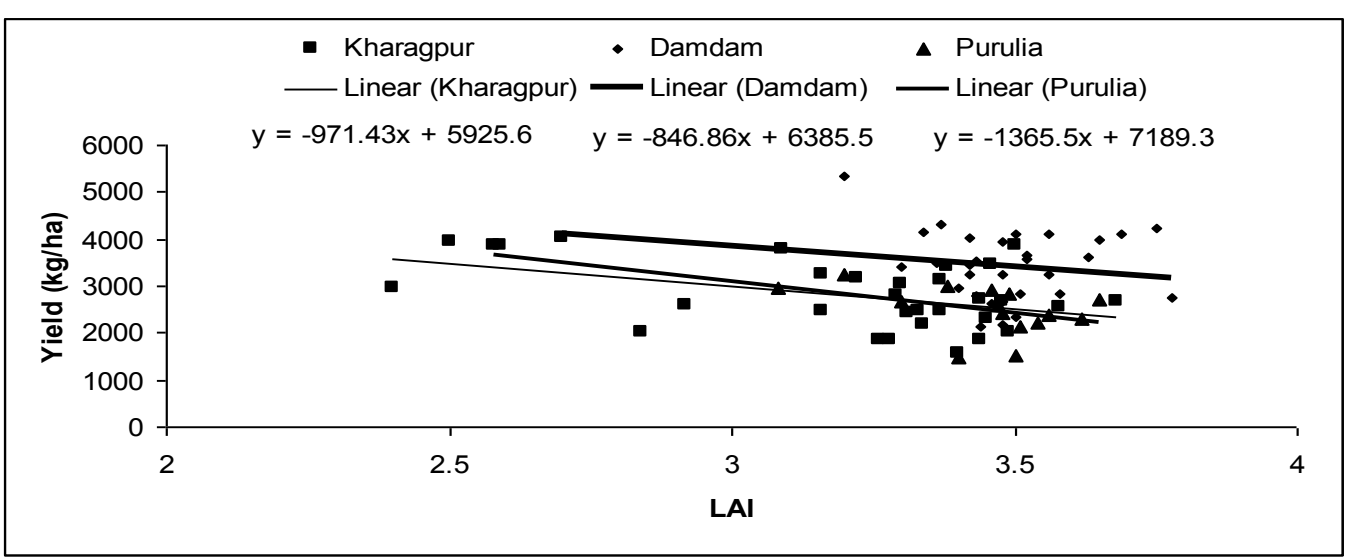

Fig. 8: Relation between maximum leaf area index and maize yield at Kharagpur, Dumdum and Purulia

\subsection{Effect of Temperature and $\mathrm{CO}_{2}$ Levels at Fixed Increments on Maize Yield}

Carbon dioxide is considered a greenhouse gas due to its high absorptance in several wavelengths of the thermal infrared radiation emitted by earth's surface. The greater the content of gases in the atmosphere that absorb thermal infrared radiation emitted from the earth surface, the greater the thermal infrared radiation emitted by the atmosphere towards the earth surface. Consequently, the long wave balance of the surface will be less negative and more energy will be available for latent and sensible heat fluxes at the earth's surface. As more energy is available for sensible heat flux, air temperature is expected to rise. If the increase in atmospheric $\mathrm{CO}_{2}$ concentration is accompanied by an increase in air temperature, crops may shorten their growth cycle, which may offset the advantages of an increasing $\mathrm{CO}_{2}$ concentration. Therefore, the interacting effects of $\mathrm{CO}_{2}$ concentration and temperature on plant growth are complicated. $\mathrm{CO}_{2}$ is a component of plant photosynthesis and therefore influences biomass production. It also regulates the opening of plant stomata and therefore affects plant transpiration. As a result, plants growing in increased $\mathrm{CO}_{2}$ conditions will produce more biomass and will consume less water.

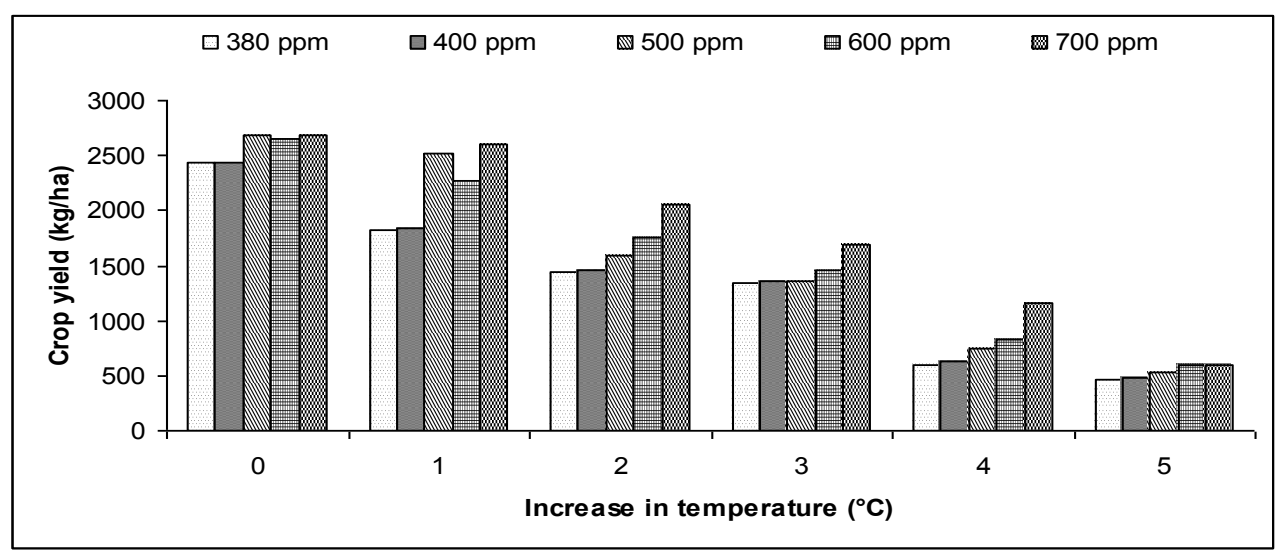

Fig. 9: Variation in simulated maize yield under incremental atmospheric $\mathrm{CO}_{2}$ concentrations 
The potential yield of maize was simulated at Kharagpur using the crop growth model under the combinations of $\mathrm{CO}_{2}$ and temperature with fixed increments in $\mathrm{CO}_{2}$ concentrations $(380,400$, 500,600 and $700 \mathrm{ppm}$ ) and temperatures (ambient, $+1,+2,+3,+4,+5{ }^{\circ} \mathrm{C}$ ) individually and with all combinations of $\mathrm{CO}_{2}$ and temperature for the year 1996. At all the $\mathrm{CO}_{2}$ levels tested, the simulated maize yield decreased due to an increase in temperature. On the other hand for an increase in $\mathrm{CO}_{2}$ level at any particular temperature, maize yields found to be increased (Fig. 9). Similar trends of crop yield were obtained by $[17,18,19]$. He estimated that a doubling of $\mathrm{CO}_{2}$ concentration, holding other factors constant, could lead to a $34 \pm 6 \%$ increase in agricultural yields of C3 plants. Similarly, Lawlor and Mitchell [23] found that under availability of adequate water, nutrients and pest control, yield of $\mathrm{C} 3$ crops growing in about $700 \mathrm{ppm} \mathrm{CO}_{2}$ would be about 30 to $40 \%$ greater than the present yield.

\subsection{Effect of Change in Sowing Date on Maize Yield}

Different studies have suggested that adjusting the sowing dates and determining the optimum dates for sowing will be helpful in reducing the effect of climate change [4, 21]. Adjustment of management practices may help to offset any detrimental effects of climate change on maize production. Probably the easiest adaptation strategy to cope with climate change is to adjust the sowing dates. The selection of an earlier sowing date for maize will probably be the appropriate response to offset the negative effect of a potential increase in temperature. This change in planting date will allow for the crop to develop during a period of the year with lower temperatures, thereby decreasing developmental rates and increasing the growth duration, especially the grain filling period. Adjustment of sowing date and simulation of its effect was done using the model to investigate a suitable agronomic option for adaptation under the future climate change scenarios.

The potential outcome of adjusting the sowing dates at Kharagpur, Dumdum and Purulia was simulated using the CERES-maize model for the year 1996 to assess the effect of climate change, as shown in Fig. 10. To determine the optimum sowing dates the potential outcomes were studied by shifting the sowing dates 3 weeks before and 4 weeks after the actual date of sowing $\left(6^{\text {th }}\right.$ February) at an interval of one week. The maize yield was simulated for each date and the percentage change in yield corresponding to the experimental yield for actual sowing date was calculated. Among the different sowing dates considered, the sowing date of $30^{\text {th }}$ January, that is one week before the actual sowing date was considered to be the most beneficial for Kharagpur and Dumdum in terms of increase in yield. For Purulia, $6^{\text {th }}$ February was found to be the most appropriate date of sowing. When the date of sowing was shifted a week ahead with respect to actual, an increase of $25 \%$ and $12 \%$ in yield was observed for Dumdum and Kharagpur respectively. It should be noted, however, that although changes in sowing date are a no-cost decision that can be taken at the farm-level, a large shift in sowing dates probably would interfere with the agrotechnological management of other crops, grown during the remainder of the year. 


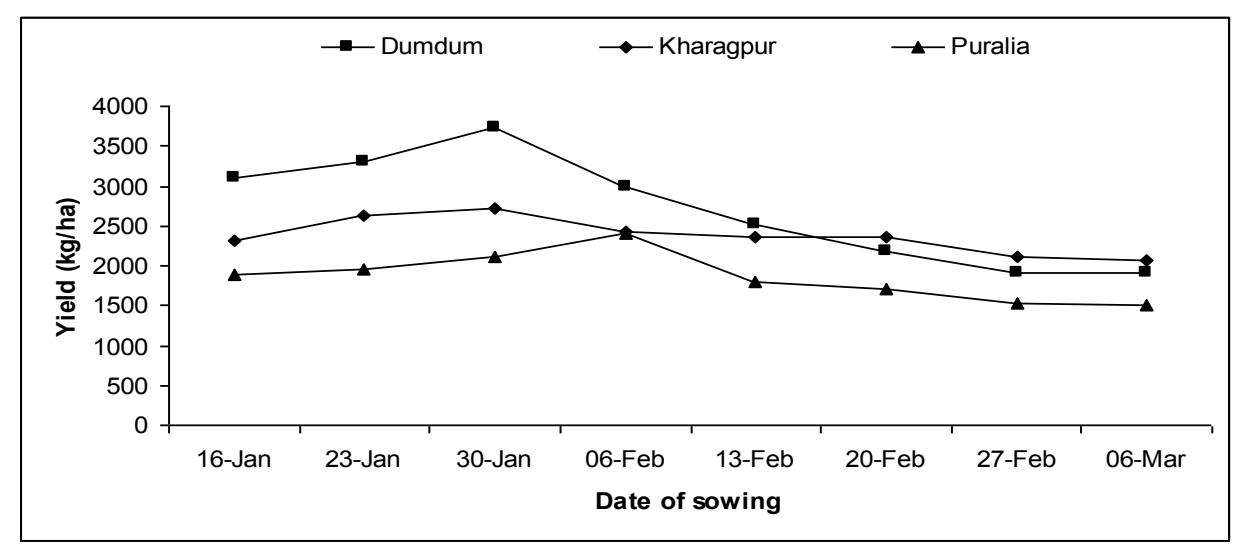

Fig. 10: Variation in maize yield with change in sowing dates at Kharagpur, Dumdum and Purulia

\section{Summary and Conclusions}

Climate change is one of the major challenges being faced by the world in coming decades. It is affecting almost every sector including food and water and is becoming a threat to global food security. Maize being the third most important food crop in the world requires special attention and immediate mitigation measures to achieve food security under changed climate scenarios. The objectives of this study were to simulate the maize yield under various climate change scenarios and to identify the possible adaptation measures to reduce the negative impact of climate change on yield using CERES-Maize model. The study was conducted using secondary data collected on crop management, climate and soil. The CERES-Maize model was calibrated and validated using the experimental data for maize at Kharagpur during the three consecutive years from 1996 to 1998 . The maize yield was simulated using the historical climate data at Kharagpur (1977-2007), Dumdum (1974-2003) and Purulia (1986-2000) with the help of calibrated model. The model was used to study the impacts of temperature, solar radiation and leaf area index on growth and yield of maize at the three locations. The effect of elevated temperature and $\mathrm{CO}_{2}$ on maize yield was also studied. A study was done to assess the effect of developed scenarios on maize yield. The model was also used to assess the suitable date of sowing, suitable plant density and appropriate nitrogen doze in the climate change scenarios. Based on the results of the study, the conclusions are: (i) There is no trend for solar radiation, maximum temperature and minimum temperature at Kharagpur and Purulia but there is increasing trend for solar radiation, no trend for maximum temperature and decreasing trend for minimum temperature at Dumdum, (ii) Calibrated CERES-Maize model can be used for the simulation of maize yield in this subtropical climate region, (iii) Increase in mean temperature and maximum leaf area index have a negative impact on maize yield, (iv) Increase in temperature affects maize yield negatively while increase in $\mathrm{CO}_{2}$ concentration has positive effect on maize yield and (v) Selection of alternate sowing dates may help to mitigate the negative effects of climate change. Shifting the sowing date a week ahead than the experimental date $\left(6^{\text {th }} \mathrm{Feb}\right)$ is found to be beneficial for Kharagpur and Dumdum whereas for Purulia, the experimental date of sowing is beneficial. 


\section{References}

[1] Aggarwal PK, Kalra N, Singh AK and Sinha SK (1994), Analyzing the limitations set by the climatic factors, genotype, water and nitrogen availability on productivity of wheat I. The model documentation, parameterization and validation, Field Crop Research, 38(2) : 73-91.

[2] Bacastow RB (1985), Seasonal amplitude increase in atmospheric $\mathrm{CO}_{2}$ concentration at Mauna Loa, Hawaii, 1959- 1982, Journal of Geophysical Research, 90 : 529-540.

[3] Baes CF (1977), Carbon dioxide and climate: the uncontrolled experiment, American Scientist, $65: 310-320$.

[4] Baker JT and Allen Jr. LH (1993), Effects of $\mathrm{CO}_{2}$ and temperature on rice: A summary of five growing seasons, Journal of Agricultural Meteorology, 48(5) a: 575-582.

[5] Bannayan M, Hoogenboom G and Crout NMJ (2004), Photothermal impact on maize performance: a simulation approach, Ecological Modelling, 180(2-3) : 277-290.

[6] Bradley RG (1994), Modelling the growth and water use of tropical cereals in semiarid environments. University of Nottingham, UK.

[7] Burns DA, Klaus J and McHale MR (2007), Recent climate trends and implications for water resources in the Catskill Mountain region, New York, USA, Journal of Hydrology, 336(1-2) :155-170.

[8] Cubasch U, Meehl GA, Boer GJ, Stouffer RJ, Dix M, Noda A, Senior CA, Raper S and Yap KS (2001), Projections of future climate change, in: Houghton JT, Ding Y, Griggs DJ, Noguer M, van der Linden P, Dai X, Maskell K and Johnson CI (editors), Climate Change 2001: The Scientific Basis, Contribution of Working Group I to the Third Assessment Report of the Intergovernmental Panel on Climate Change, Cambridge University Press, UK, pp. 525-582.

[9] Dhakhwa GB and Campbell CL (1998), Potential effects of differential day-night warming in global climate change on crop production, Climatic Change, 40 : 647-667.

[10] Dhakhwa GB, Campbell CL, LeDuc SK and Cooter EJ (1997), Corn growth: assessing the effects of global warming and $\mathrm{CO}_{2}$ fertilization with crop models, Agricultural and Forest Meteorology, 87 : 253-272.

[11] Feidas H, Makrogiannis T and Bora-Senta E (2004), Trend analysis of air temperature time series in Greece and their relationship with circulation using surface and satellite data: 19552001, Theoretical and Applied Climatology, 79: 185-208.

[12] Goosens C and Berger A (1986), Annual and seasonal climatic variations over the Northern Hemisphere and Europe during the last century, Annales Geophysics, 35 : 385-400.

[13] Hoogenboom G, Jones JW, Wilkens PW, Batchelor WD, Bowen WT, Hunt LA, Pickering NB, Singh U, Godwin DC, Baer B, Boote KJ, Ritchie JT and White JW (1994), Crop models, in: Tsuji GY, Uehara G and S Balas (editors), DSSAT v3. Vol 2-2, University of Hawaii, Honolulu, Hawaii.

[14] IPCC (2001), Climate Change 2001: the scientific basis - contribution of the working group I to the third assessment report International Panel on Cress, UK.

[15] Kaiser HM, Riha SJ, Wilks DS and Sampath R (1995), Adaptation to global climate change at the farm level, in: Kaiser HM and Drennen TE (editors), Agricultural Dimensions of Global Change. St. Lucie Press, Florida, USA, pp. 136-152.

[16] Kendall MG (1975), Rank correlation methods. $4^{\text {th }}$ edition, Griffin, London, pp. 55. 
[17] Kimball BA (1983a), Carbon dioxide and agricultural yield: An assemblage and analysis of 430 prior observations, Agronomy Journal, 75 : 779-788.

[18] Kimball BA (1983b), Carbon dioxide and agricultural yield: An assemblage and analysis of 770 prior observations. Phoenix: US Water Conservation Laboratory. Water Conservation Laboratory Report, No. 14.

[19] Kimball BA (1986), Influence of elevated $\mathrm{CO}_{2}$ on crop yield, in: Enoch $\mathrm{HZ}$ and Kimball BA (editors), Carbon dioxide enrichment of greenhouse crops: physiology, yield and economics, Boca Raton: CRC, pp. 105-115.

[20] Kumar KSK and Parikh J (2001b), Indian Agriculture and Climate Sensitivity, Global Environmental Change, 11(2) : 147-154.

[21] Kupkanchanakul T (2000), Bridging the Rice Yield Gap in Thailand, in: Papademetriou MK, Dent FJ and Herath EM (editors), Bridging the Rice Yield Gap in Asia and the Pacific, 5-7 October 1997, Bangkok, Thailand, RAP Publication, 16 p.

[22] Lal M, Singh KK, Rathore LS, Srinivasan G and Saseendran SA (1998), Vulnerability of rice and wheat yields in NW India to future changes in climate, Agricultural and Forest Meteorology, 89(2) : 101-114.

[23] Lawlor DW and Mitchell RAC (1991), The effects of increasing $\mathrm{CO}_{2}$ on crop photosynthesis and productivity: a review of field studies. Plant, Cell and Environment, 14 : 807-818.

[24] Long SP, Ainsworth EA, Rogers A and Ort DR (2004), Rising atmospheric carbon dioxide: plants face the future, Annual Review of Plant Biology, 55 : 591-628.

[25] Mahlman JD (1997), Uncertainties in projections of humaninduced climate warming, Science, 278 : 1416-1417.

[26] Mall RK, Singh R, Gupta A, Srinivasan G and Rathore LS (2006). Impact of Climate Change on Indian Agriculture: A Review. Climatic Change, 78(2-4): 445-478.

[27] McCarthy JJ, Canziani OF, Leary NA, Dokken DJ and White KS (2001), Climate Change 2001: Impacts, Adaptation, and Vulnerability. Contribution of Working Group II to the Third Assessment Report of the Intergovernmental Panel on Climate Change.

[28] Ong CK and Monteith JL (1985), Response of pearl millet to light and temperature, Field Crops Research, 11 : 141-160.

[29] Oosterom EJ van. O'Leary, GJ, Carberry PS and Craufurd PQ (2002), Simulating growth, development and yield of tillering pearl millet. III. Biomass accumulation and partitioning, Field Crop Research, 79(2-3): 85-106.

[30] Pearce F (1997), State of the Climate - A Time for Action. WWF Report.

[31] Phillips DL, Lee JJ and Dodson RF (1996), Sensitivity of the US corn belt to climate change and elevated $\mathrm{CO}_{2}$ I. Corn and soybean yields, Agricultural Systems, 52(4) : 481-502.

[32] Ritchie JT, Singh U, Godwin DC and Bowen WT (1998), Cereal growth, development and yield, in: Tsuji GY (editor), Understanding Options for Agricultural Production, Kluwer Academic Publishers, Great Britain, pp. 79-98.

[33] Rosenzweig C and Hillel D (1998), Climate Change and the Global Harvest: Potential Impacts of the Greenhouse Effect on Agriculture. Oxford University Press, New York.

[34] Rosenzweig C, Allen LH, Harper LA, Hollinger SE and Jones JW (1995), Climate Change and Agriculture: Analysis of Potential International Impacts. ASA Special Publication No. 59. ASA, Madison, WI. 
[35] Schlenker W and Roberts MJ (2006). Nonlinear effects of weather on corn yields, Review of Agricultural Economics, 28: 391-398.

[36] Steiner JL, Howell TA, Tolk JA and Schneider AD (1991), Evapotranspiration and growth predictions of CERES-Maize, sorghum and wheat in the southern high plains, Proceedings of the 1991 National Conference, ASCE Honolulu, Hawaii, USA, 22-26.

[37] Uehara G and Tsuji GY (1998), Overview of IBSNAT, in: Tsuji GY, Hoogenboom G and Thornton PK (editors), Understanding Options for Agricultural Production, Kluwer Academic Publishers, Dordrecht, The Netherlands, pp 1-7.

[38] Wafula BM (1995), Applications of crop simulation in agricultural extension and research in Kenya, Agricultural Systems, 49(4): 399-412.

[39] Warrington IJ and Kanemasu ET (1983a), Corn growth response to temperature and photoperiod. I. Seedling emergence, tassel initiation, and anthesis, Agronomy Journal, 75: 749-754.

[40] White JW, Hoogenboom G and Hunt LA (2005), A Structured Procedure for Assessing How Crop Models Respond to Temperature, Agronomy Journal, 97(2) : 426-439. 